\title{
Neuroendocrine and Behavioral Responses and Brain Pattern of c-fos Induction Associated with Audiogenic Stress
}

\author{
Serge Campeau and Stanley J. Watson \\ Mental Health Research Institute, The University of Michigan, 205 Zina Pitcher Place, Ann Arbor, MI 48109, USA.
}

Key words: activity, auditory, histochemistry, corticosterone, noise, rat.

\begin{abstract}
The present study determined simultaneously the behavioural, neuroendocrine and regional brain activity, using semi-quantitative analysis of c-fos mRNA induction, produced by 30 min of auditory stimulation at different white noise intensities (background 60 dB, 70, 80,90 and $105 \mathrm{dBA}$ ), in rats. Only the highest noise intensities (90 and $105 \mathrm{~dB}$ ) significantly increased corticosterone release after 30 min stimulation. Behaviourally, the $105 \mathrm{~dB}$ noise condition reliably reduced overall activity, and moderate noise intensities (70 and $80 \mathrm{~dB})$ increased sleeping time. Three distinct patterns of c-fos mRNA induction were observed. First, following exposure to the experimental cages, a wide pattern of brain activation was obtained in experimental animals irrespective of noise intensity presentation, compared to the naive rats. Second, a number of auditory structures (cochlear nuclei, superior olivary complex, nuclei of the lateral lemniscus, inferior colliculus and the medial division of the medial geniculate body) displayed a clear intensity-dependent increase in c-fos induction. Third, compared to all other conditions, the stressed rats (90 and $105 \mathrm{~dB}$ conditions) displayed significantly higher c-fos induction in relatively few areas. Particularly intense c-fos induction was observed in the bed nucleus of the stria terminalis, especially its anterior medial and ventral aspects, the septohypothalamic nucleus, the ventral lateral septum, the ventral portion of the dentate gyrus, a number of hypothalamic nuclei including the lateral preoptic area, the medial preoptic nucleus and the paraventricular nucleus, the median raphe and the pedunculopontine tegmental nucleus. The involvement of a number of these structures in a specific audiogenic stress responsive circuit is discussed.
\end{abstract}

Recently, immediate-early genes (e.g. c-fos, c-jun, zif/268) have been used as neuroanatomical markers to determine the pattern of brain activity and neural pathways associated with a variety of stressors (1-14). The few detailed and quantitative analyses of immediate-early gene expression have revealed that physical or psychological stressors (restraint/immobilization, forced swim and fear) appear to activate a large number of brain areas (1, 11). Because many brain areas were commonly activated by the above stressors, these regions have been proposed to underlie a neural system reflecting a general state of stress. However, this conclusion might be premature because most of the above stress conditions cannot be controlled easily, and therefore, some of the regional activity detected might reflect processes that are not specific to the specific stress stimuli employed.

The main goal of the present study was to use increasing intensities of white noise to determine the specific brain areas, using semi-quantitative analysis of the immediate early gene cfos, involved in audiogenic stress. Acoustic stimulation, which can be graded from non-stress to stressful levels, was used to help control for processes other than those directly responsible for audiogenic stress. To determine the stressful nature of increasing auditory stimulation, the levels of plasma corticosterone were measured, as a reliable index of hypothalamo-pituitary-adrenal activation induced by a variety of stressful conditions, including loud auditory stimulation (15-21). In addition, behaviour was monitored since previous studies have established that overall activity is reliably reduced by loud noise stimulation (19-21). The data obtained indicate that a limited number of brain regions are selectively activated in rats stressed with loud noise, as measured with c-fos mRNA induction.

\section{Results}

Plasma corticosterone release evoked by the exposure of rats to $30 \mathrm{~min}$ of white noise at various intensities, or in naive control rats, is presented in Fig. 1. One-way ANOVA revealed a significant effect of the different noise intensities, $\mathrm{F}(5,18)=18.87, \mathrm{P}<0.001$. Post-hoc multiple mean comparisons (Tukey) indicated that rats from the 2 higher noise intensity groups (90 and $105 \mathrm{~dB}$ ) had significantly higher plasma corticosterone levels compared to all other groups, but were not different from each other $(\mathrm{P}<0.05)$. No other differences were obtained.

The behaviour of rats from the different noise intensity conditions also showed reliable differences, as shown in Fig. 2. Mean

Correspondence to: Serge Campeau, Mental Health Research Institute, The University of Michigan, 205 Zina Pitcher Place, Ann Arbor, MI 48109-0720, USA. 


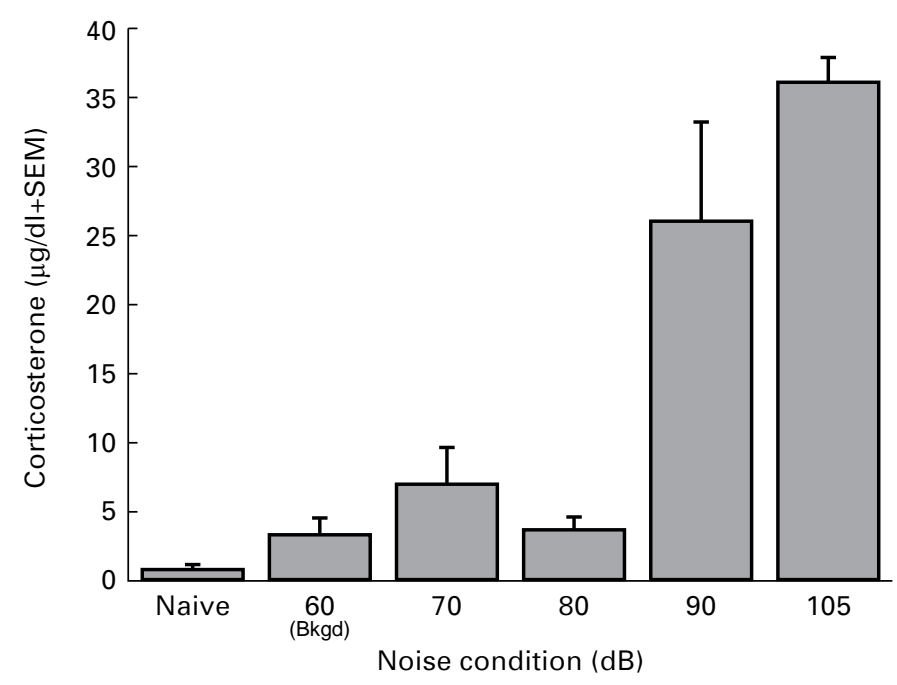

FIG. 1. Plasma corticosterone values $(\mu \mathrm{g} / \mathrm{dl}+\mathrm{SEM})$ in each of the noise conditions obtained from trunk blood $30 \mathrm{~min}$ following initiation of noises at the different intensities or after cage placement ( $60 \mathrm{~dB} \mathrm{Bkgd})$, or immediately upon removal from the home cages (Naive).

immobility scores were reliably different between the various noise intensity conditions, $\mathrm{F}(4,15)=5.42, \mathrm{P}<0.01$, particularly for the last $20 \mathrm{~min}$. Multiple mean comparisons indicated that rats from the $105 \mathrm{~dB}$ condition were more immobile than rats from other conditions, especially during the last time period. Total active behaviours (sum of locomotion, rearing and grooming behaviours) were also reliably different over the entire noise session, $\mathrm{F}(4,15)=4.41, \mathrm{P}<0.05$, particularly during the last 20 min. This was mainly due to lower overall activity from rats in the $105 \mathrm{~dB}$ condition. The reduced active behaviours observed in the 70 and $80 \mathrm{~dB}$ conditions could be attributed to increased sleeping time in those groups, as revealed by a significant Condition $\times$ Time period interaction, $\mathrm{F}(20,75)=2.59, \mathrm{P}<0.005$. Rats from the 70 and $80 \mathrm{~dB}$ groups displayed significantly more sleeping during the last time period $(25-30 \mathrm{~min})$ than any other group, $\mathrm{F}(4,15)=12.35, \mathrm{P}<0.001$, but were not different from each other.

C-fos mRNA was widely induced in the brains of rats decapitated $30 \mathrm{~min}$ following the beginning of different noise intensity conditions, as measured by semi-quantitative integrated densitometric measurements from x-ray films presented in Table 1. A majority (65) of the 71 brain regions analysed displayed reliable c-fos induction in one or more of the experimental conditions, compared to the naive rats (ANOVAs, $\mathrm{P}<0.05$ ). Representative examples of c-fos induction in the naive, 60, 80 and $105 \mathrm{~dB}$ conditions are presented at eight levels of the neuraxis in Figures 3 and 4.

Many of the regions (31) quantified displayed c-fos induction above naive levels, irrespective of noise intensity. Thus, simply placing rats in the experimental boxes in which they had previously been exposed for nine days ( $60 \mathrm{~dB}$ background condition) was sufficient to reliably induce c-fos in many brain areas that was not statistically exceeded by presentation of louder noise intensities (up to $105 \mathrm{~dB}$, see Table 1). This was notable in the amygdala, thalamus and cortex, and a few additional structures in the hippocampus, midbrain, pons and brainstem. This is depicted in
Fig. 5 for some areas in standardized scores $(z)$ from the raw integrated densities. Presentation of white noise 10 or $20 \mathrm{~dB}$ above background level (70 and $80 \mathrm{~dB}$ conditions, respectively) produced a pattern of c-fos induction remarkably similar to the $60 \mathrm{~dB}$ background noise condition, except for moderately higher induction in some auditory areas.

Many auditory areas, including the cochlear nuclei, superior olivary complex, nuclei of the lateral lemniscus, external nucleus of the inferior colliculus and the medial division of the medial geniculate body, showed increasing c-fos induction with increasing noise intensities. Figure 6 illustrates all the auditory areas measured and the intensity-dependent c-fos induction relationship obtained in many of these areas.

Exposure of rats to noise intensities ( 90 and/or $105 \mathrm{~dB}$ noise conditions) which evoked reliable corticosterone release, resulted in additional but limited regional c-fos induction that was significantly greater than that observed in rats from all other groups (Naive, 60, 70 and $80 \mathrm{~dB}$ ). These regions, depicted in Fig. 7, included the anterior bed nucleus of the stria terminalis (medial and ventral), septohypothalamic nucleus, ventral dentate gyrus, lateral preoptic area, medial preoptic and paraventricular nuclei of the hypothalamus, median raphe and the pedunculopontine tegmental nucleus. Four brain areas from rats in the 90 and/or $105 \mathrm{~dB}$ conditions displayed reliable c-fos induction compared to the Naive, $60 \mathrm{~dB}$ background and $70 \mathrm{~dB}$ conditions; the lateral septum (ventral), supramammillary nucleus, laterodorsal central gray and the central/dorsal nuclei of the inferior colliculus. The lateral nucleus of the amygdala, the superior colliculus and the laterodorsal tegmental nucleus from rats in the $90 \mathrm{and} /$ or $105 \mathrm{~dB}$ conditions showed higher c-fos induction compared to the Naive and $60 \mathrm{~dB}$ background conditions. Six additional brain areas from rats in the 90 and/or $105 \mathrm{~dB}$ conditions, namely the nucleus accumbens (mostly shell), ventromedial nucleus of the hypothalamus, ventral posterior and oculomotor nuclei of the thalamus, dorsal raphe and the dorsal tegmental nucleus, showed reliable c-fos induction only compared to Naive rats. The auditory nuclei of the lateral lemniscus were the only regions in which c-fos induction between the 90 and $105 \mathrm{~dB}$ conditions was reliably different.

\section{Discussion}

Exposing rats to white noise intensity levels of $90 \mathrm{~dB}$ or greater reliably evoked the release of corticosterone, as reported previously with loud auditory stimulation (15-21). The present results, however, offer the first clear demonstration of a noise intensity dependent corticosterone release function, with a threshold for activation at $\approx 90 \mathrm{~dB}$ ( $30 \mathrm{~dB}$ above background noise levels). The reduced behavioural activity of rats exposed to the highest noise intensity $(105 \mathrm{~dB})$ is also consistent with the results of prior studies (19-21), whereas the lack of behavioural inhibition to $90 \mathrm{~dB}$ exposure has not been reported or examined previously. This dissociation between the behavioural and neuroendocrine effects of $90 \mathrm{~dB}$ exposure deserves additional attention. The longer sleep duration observed particularly in rats from the 70 and $80 \mathrm{~dB}$ conditions provides one of the first report of experimentally induced increases in one of various sleep variables by steady state noise of moderate intensity in animals, as has been shown in newborn and adult humans (22-24).

c-fos was broadly induced in the brains of control rats 

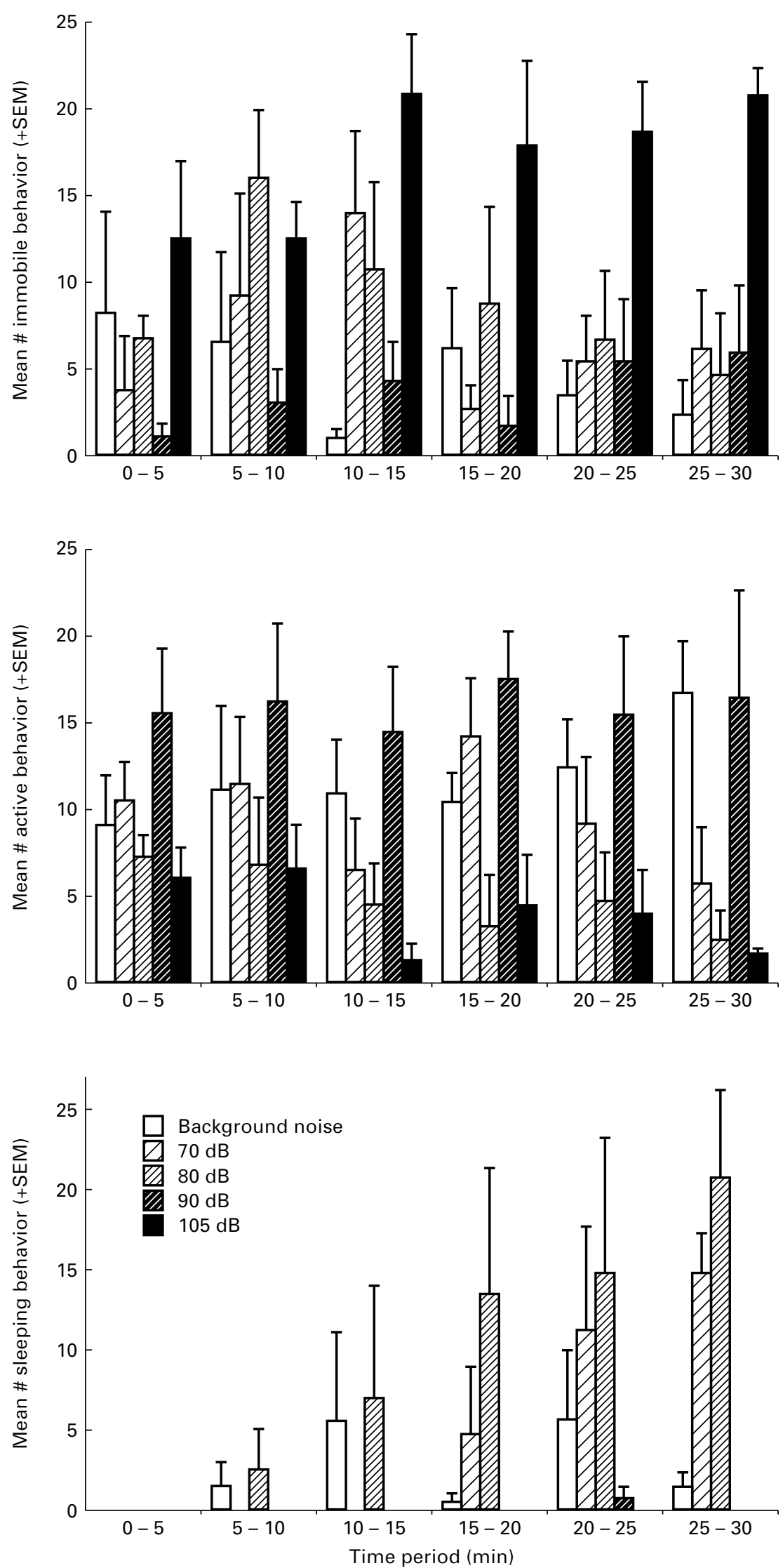

FIG. 2. Sampling of immobile (top), active (middle) and sleeping (bottom) behaviors (+ SEM) in rats exposed to background noise (60), 70, 80, 90, or 105 dB. (C) 1997 Blackwell Science Ltd, Journal of Neuroendocrinology, 9, 577-588 
TABLE 1. Mean Integrated Densities (/100 \pm SEM $)$.

\begin{tabular}{|c|c|c|c|c|c|c|c|c|c|c|c|c|}
\hline \multirow[b]{2}{*}{ Brain region } & \multicolumn{12}{|c|}{ Experimental group } \\
\hline & \multicolumn{2}{|l|}{ Naive } & \multicolumn{2}{|l|}{$60 \mathrm{~dB}$} & \multicolumn{2}{|l|}{$70 \mathrm{~dB}$} & \multicolumn{2}{|l|}{$80 \mathrm{~dB}$} & \multicolumn{2}{|l|}{$90 \mathrm{~dB}$} & \multicolumn{2}{|l|}{$105 \mathrm{~dB}$} \\
\hline Forebrain & & & & & & & & & & & & \\
\hline Nucleus accumbens $\dagger$ & 23 & (11) & 38 & (15) & 41 & (17) & 33 & (14) & $132^{\mathrm{a}}$ & (21) & $159^{\mathrm{a}}$ & (12) \\
\hline BNST medial $†$ & 0.3 & $(0.1)$ & $8.3^{\mathrm{a}}$ & $(2.0)$ & $12^{\mathrm{a}}$ & (5.3) & $9.6^{\mathrm{a}}$ & $(2.2)$ & $74^{\mathrm{d}}$ & (19) & $99^{\mathrm{d}}$ & (25) \\
\hline BNST ventral $\dagger$ & 1.1 & $(0.6)$ & $6.0^{\mathrm{a}}$ & $(1.2)$ & $5.8^{\mathrm{a}}$ & $(1.4)$ & $7.8^{\mathrm{a}}$ & (3.2) & $32^{\mathrm{a}}$ & (6.1) & $36^{\mathrm{d}}$ & $(4.0)$ \\
\hline Caudate nucleus dorsal $\dagger$ & 17 & (3) & 134 & (52) & $283^{\mathrm{a}}$ & (208) & 89 & (47) & $262^{\mathrm{a}}$ & (93) & $123^{\mathrm{a}}$ & (21) \\
\hline Caudate nucleus ventral $\dagger$ & 5.3 & $(2.6)$ & $196^{\mathrm{a}}$ & (165) & 54 & (39) & 13 & (5.8) & 35 & (14) & 13 & (3.7) \\
\hline Dorsal endopiriform nuc $\dagger$ & 4.6 & $(2.7)$ & $64^{\mathrm{a}}$ & (16) & $72^{\mathrm{a}}$ & (27) & $57^{\mathrm{a}}$ & (14) & $81^{\mathrm{a}}$ & (3.5) & $66^{\mathrm{a}}$ & $(4.5)$ \\
\hline Medial septum $\dagger$ & 1.2 & $(0.4)$ & $10^{\mathrm{a}}$ & (3.2) & $6.7^{\mathrm{a}}$ & (1.3) & $13^{\mathrm{a}}$ & (7.7) & $16^{\mathrm{a}}$ & (2.6) & $13^{\mathrm{a}}$ & (3.3) \\
\hline Lateral septum $\dagger$ & 0.9 & $(0.3)$ & $92^{\mathrm{a}}$ & (67) & $45^{\mathrm{a}}$ & (18) & $86^{\mathrm{a}}$ & (29) & $448^{c}$ & (34) & $592^{\mathrm{c}}$ & (63) \\
\hline Septohypothalamic nuc $\dagger$ & 0.4 & $(0.1)$ & $21^{\mathrm{a}}$ & (11) & $18^{\mathrm{a}}$ & $(6.7)$ & $29^{\mathrm{a}}$ & $(7.0)$ & $182^{\mathrm{d}}$ & $(8.2)$ & $305^{\mathrm{d}}$ & (39) \\
\hline \multicolumn{13}{|l|}{ Amygdala } \\
\hline Anterior cortical nuclei $\dagger$ & 14 & $(5.5)$ & $95^{\mathrm{a}}$ & (32) & $114^{\mathrm{a}}$ & (34) & $66^{\mathrm{a}}$ & $(15)$ & $95^{\mathrm{a}}$ & (14) & $108^{\mathrm{a}}$ & (17) \\
\hline Basolateral nucleus $\dagger$ & 12 & (5.8) & $53^{\mathrm{a}}$ & (12) & $77^{\mathrm{a}}$ & (32) & $59^{\mathrm{a}}$ & (11) & $91^{\mathrm{a}}$ & (19) & $74^{\mathrm{a}}$ & (4) \\
\hline Central nucleus & 14 & (7.2) & 6.3 & $(0.7)$ & 8.8 & $(2.2)$ & 10 & $(2.3)$ & 11 & $(0.4)$ & 17 & (1.4) \\
\hline Lateral nucleus $\dagger$ & 4.8 & $(2.3)$ & $24^{\mathrm{a}}$ & (3.8) & $31^{\mathrm{a}}$ & (7.1) & $30^{\mathrm{a}}$ & (4.6) & $91^{\mathrm{a}}$ & (29) & $89^{\mathrm{b}}$ & $(5.0)$ \\
\hline Medial nucleus $\dagger$ & 4.0 & $(0.9)$ & $50^{\mathrm{a}}$ & (16) & $80^{\mathrm{a}}$ & (34) & $43^{\mathrm{a}}$ & (13) & $121^{\mathrm{a}}$ & (27) & $59^{\mathrm{a}}$ & (13) \\
\hline Posterior cortical nuclei $\dagger$ & 6.2 & $(1.9)$ & $133^{\mathrm{a}}$ & (39) & $162^{\mathrm{a}}$ & (30) & $133^{\mathrm{a}}$ & (37) & $226^{\mathrm{a}}$ & (31) & $215^{\mathrm{a}}$ & (6) \\
\hline \multicolumn{13}{|l|}{ Hippocampus } \\
\hline Dentate gyrus dorsal & 41 & (11) & 41 & (11) & 61 & (11) & 43 & (18) & 85 & $(15)$ & 42 & $(2.3)$ \\
\hline Dentate gyrus ventral $\dagger$ & 3.0 & $(0.6)$ & 13 & (2.9) & 7.7 & (2.1) & 13 & (6.4) & $60^{\mathrm{a}}$ & (15) & $172^{\mathrm{d}}$ & (49) \\
\hline $\mathrm{CA} 1 \dagger$ & 5.4 & $(2.7)$ & $39^{\mathrm{a}}$ & $(2.0)$ & $45^{\mathrm{a}}$ & (20) & $39^{\mathrm{a}}$ & (11) & $80^{\mathrm{a}}$ & (31) & $39^{\mathrm{a}}$ & $(9.7)$ \\
\hline $\mathrm{CA} 2$ & 4.7 & $(2.2)$ & 13 & (1.4) & 17 & $(8.0)$ & 12 & (2.1) & 17 & (4.0) & 11 & (3.1) \\
\hline $\mathrm{CA} 3 \dagger$ & 43 & (18) & 117 & (12) & $145^{\mathrm{a}}$ & (44) & $135^{\mathrm{a}}$ & $(35)$ & $185^{\mathrm{a}}$ & (28) & 119 & (11) \\
\hline Cortex & & & & & & & & & & & & \\
\hline Cingulate $\dagger$ & 107 & (32) & $1018^{\mathrm{a}}$ & $(392)$ & $1020^{\mathrm{a}}$ & (309) & $964^{\mathrm{a}}$ & $(347)$ & $2101^{\mathrm{a}}$ & $(341)$ & $1295^{\mathrm{a}}$ & (135) \\
\hline Enthorinal $\dagger$ & 56 & (26) & $292^{\mathrm{a}}$ & (63) & $256^{\mathrm{a}}$ & (58) & $271^{\mathrm{a}}$ & $(75)$ & $382^{\mathrm{a}}$ & (72) & $263^{\mathrm{a}}$ & (16) \\
\hline Frontal & 401 & (233) & 1070 & (247) & 768 & (384) & 308 & (113) & 941 & (277) & 705 & (309) \\
\hline Infralimbic $\dagger$ & 11 & $(7.0)$ & $223^{\mathrm{a}}$ & $(115)$ & $176^{\mathrm{a}}$ & $(65)$ & $141^{\mathrm{a}}$ & $(57)$ & $269^{\mathrm{a}}$ & $(61)$ & $221^{\mathrm{a}}$ & $(41)$ \\
\hline Insular & 106 & (32) & 215 & (61) & 135 & (56) & 130 & (50) & 219 & (43) & 218 & (34) \\
\hline Lateralorbital $\dagger$ & 175 & (65) & $1604^{a}$ & $(346)$ & $2021^{\mathrm{a}}$ & (475) & $1254^{\mathrm{a}}$ & (491) & $2317^{\mathrm{a}}$ & (483) & $1682^{\mathrm{a}}$ & (173) \\
\hline Occipital (visual) $\dagger$ & 619 & (293) & $4143^{\mathrm{a}}$ & (233) & $4221^{\mathrm{a}}$ & $(815)$ & $4789^{a}$ & $(505)$ & $6932^{\mathrm{a}}$ & $(825)$ & $5353^{\mathrm{a}}$ & (288) \\
\hline Parietal $\dagger$ & 1359 & (769) & $4192^{\mathrm{a}}$ & (781) & 2549 & (758) & 2219 & $(430)$ & $4385^{\mathrm{a}}$ & (1228) & 3214 & (873) \\
\hline Perirhinal $\dagger$ & 65 & (27) & $285^{\mathrm{a}}$ & $(42)$ & $225^{\mathrm{a}}$ & (72) & $218^{\mathrm{a}}$ & $(27)$ & $461^{\mathrm{a}}$ & (108) & $352^{\mathrm{a}}$ & (17) \\
\hline Piriform ${ }^{\dagger}$ & 240 & (74) & $1005^{\mathrm{a}}$ & (129) & $1078^{\mathrm{a}}$ & (117) & $788^{\mathrm{a}}$ & (133) & $1267^{\mathrm{a}}$ & (213) & $997^{\mathrm{a}}$ & (65) \\
\hline Temporal (auditory) $\dagger$ & 844 & (257) & $2166^{\mathrm{a}}$ & (223) & $2242^{\mathrm{a}}$ & (345) & $2496^{\mathrm{a}}$ & (326) & $3606^{\mathrm{a}}$ & (227) & $3731^{\mathrm{a}}$ & $(332)$ \\
\hline Hypothalamus & & & & & & & & & & & & \\
\hline Dorsomedial nucleus $\dagger$ & 20 & (14) & $96^{\mathrm{a}}$ & (23) & $112^{\mathrm{a}}$ & $(42)$ & $116^{\mathrm{a}}$ & (30) & $284^{\mathrm{a}}$ & (38) & $298^{\mathrm{a}}$ & (27) \\
\hline Lateral nucleus $\dagger$ & 15 & (10) & $57^{\mathrm{a}}$ & (14) & 46 & (11) & 37 & (13) & $119^{\mathrm{a}}$ & (32) & $104^{\mathrm{a}}$ & (13) \\
\hline Lateral preoptic area $\dagger$ & 2.5 & $(0.9)$ & $23^{\mathrm{a}}$ & (15) & $15^{\mathrm{a}}$ & (3.8) & $20^{\mathrm{a}}$ & (6.7) & $151^{\mathrm{d}}$ & (16) & $97^{\mathrm{c}}$ & (27) \\
\hline Medial preoptic area $\dagger$ & 1.2 & $(0.4)$ & 3.5 & (1.1) & $15^{\mathrm{a}}$ & (5.1) & 9.1 & (4.6) & $29^{\mathrm{a}}$ & (15) & 9.1 & (2.7) \\
\hline Medial preoptic nucleus $\dagger$ & 2.1 & $(0.6)$ & $31^{\mathrm{a}}$ & (13) & $27^{\mathrm{a}}$ & $(5.2)$ & $35^{\mathrm{a}}$ & $(8.8)$ & $110^{\mathrm{c}}$ & (22) & $166^{\mathrm{d}}$ & (27) \\
\hline Paraventricular nucleus $\dagger$ & 1.2 & $(0.6)$ & $14^{\mathrm{a}}$ & (4.5) & $17^{\mathrm{a}}$ & (4.1) & $15^{\mathrm{a}}$ & (4.1) & $102^{\mathrm{d}}$ & (27) & $185^{\mathrm{d}}$ & (46) \\
\hline Supramammillary nucleus $\dagger$ & 6.6 & $(2.0)$ & $65^{\mathrm{a}}$ & (26) & $63^{\mathrm{a}}$ & (15) & $86^{\mathrm{a}}$ & (30) & $179^{\mathrm{a}}$ & (16) & $302^{c}$ & (14) \\
\hline Ventromedial nucleus $\dagger$ & 1.9 & $(0.7)$ & 2.7 & $(0.6)$ & 6.8 & (3.9) & 5.3 & $(1.5)$ & $35^{\mathrm{a}}$ & (26) & $14^{\mathrm{a}}$ & $(0.8)$ \\
\hline Thalamus & & & & & & & & & & & & \\
\hline Anterodorsal nucleus & 48 & (7.1) & 97 & $(30)$ & 66 & (19) & 54 & (14) & 95 & (12) & 96 & (12) \\
\hline Anteroventral nucleus $\dagger$ & 37 & (11) & $315^{\mathrm{a}}$ & (71) & $247^{\mathrm{a}}$ & (45) & $165^{\mathrm{a}}$ & (16) & $360^{\mathrm{a}}$ & (33) & $269^{a}$ & (41) \\
\hline Anterior pretectal nucleus $\dagger$ & 50 & (18) & $267^{\mathrm{a}}$ & (51) & $219^{\mathrm{a}}$ & (57) & $247^{\mathrm{a}}$ & (72) & $342^{\mathrm{a}}$ & (83) & $297^{\mathrm{a}}$ & $(60)$ \\
\hline Central nuclei $†$ & 68 & (34) & $351^{\mathrm{a}}$ & (82) & $282^{\mathrm{a}}$ & (82) & $322^{\mathrm{a}}$ & (56) & $589^{\mathrm{a}}$ & (127) & $489^{\mathrm{a}}$ & (78) \\
\hline Habenula $\dagger$ & 13 & (1.9) & $92^{\mathrm{a}}$ & (22) & $58^{\mathrm{a}}$ & $(8)$ & $51^{\mathrm{a}}$ & (9) & $92^{\mathrm{a}}$ & (17) & $112^{\mathrm{a}}$ & (14) \\
\hline Lateral posterior nuclei $\dagger$ & 39 & (18) & $389^{\mathrm{a}}$ & (78) & $297^{a}$ & (65) & $294^{\mathrm{a}}$ & (31) & $573^{\mathrm{a}}$ & (85) & $467^{\mathrm{a}}$ & (48) \\
\hline Lateral geniculate $\dagger$ & 146 & (22) & $701^{\mathrm{a}}$ & (106) & $630^{\mathrm{a}}$ & (73) & $579^{\mathrm{a}}$ & (96) & $783^{\mathrm{a}}$ & (130) & $646^{\mathrm{a}}$ & (84) \\
\hline Medial geniculate medial $\dagger$ & 3.7 & $(0.6)$ & $34^{\mathrm{a}}$ & (6.8) & $37^{\mathrm{a}}$ & $(3.6))$ & $56^{\mathrm{a}}$ & (14) & $143^{\mathrm{d}}$ & (15) & $173^{\mathrm{d}}$ & $(3.1))$ \\
\hline Medial geniculate ven/dor $\dagger$ & 13 & $(4.2)$ & $274^{\mathrm{a}}$ & $(65)$ & $279^{\mathrm{a}}$ & (76) & $221^{\mathrm{a}}$ & $(60)$ & $537^{\mathrm{a}}$ & (64) & $527^{\mathrm{a}}$ & (24) \\
\hline Mediodorsal nucleus $\dagger$ & 34 & (17) & $442^{\mathrm{a}}$ & (123) & $452^{\mathrm{a}}$ & (104) & $397^{\mathrm{a}}$ & (103) & $618^{\mathrm{a}}$ & (122) & $517^{\mathrm{a}}$ & $(88)$ \\
\hline Oculomotor nucleus & 13 & (5.3) & 43 & $(5.9)$ & 57 & (23) & 40 & (21) & $98^{\mathrm{a}}$ & (10) & $80^{\mathrm{a}}$ & (12) \\
\hline Paraventricular nucleus $\dagger$ & 22 & (4.1) & $178^{\mathrm{a}}$ & (47) & $167^{\mathrm{a}}$ & (41) & $191^{\mathrm{a}}$ & (26) & $331^{\mathrm{a}}$ & (41) & $346^{\mathrm{a}}$ & (26) \\
\hline Ventral posterior nucleus $\dagger$ & 39 & (16) & 141 & (30) & 137 & (59) & 126 & (46) & $343^{\mathrm{a}}$ & (114) & $262^{\mathrm{a}}$ & (76) \\
\hline Subparafascicular nucleus $\dagger$ & 1.8 & (1.3) & $33^{\mathrm{a}}$ & (22) & $32^{\mathrm{a}}$ & (5.9) & $54^{\mathrm{a}}$ & (16) & $51^{\mathrm{a}}$ & (4.1) & $152^{\mathrm{a}}$ & (33) \\
\hline Midbrain, pons, brainstem & & & & & & & & & & & & \\
\hline Dorsolateral central gray $\dagger$ & 1.9 & $(0.7)$ & 13 & $(5.3)$ & $17^{\mathrm{a}}$ & (7.3) & $18^{\mathrm{a}}$ & (6.6) & $111^{\mathrm{a}}$ & (73) & $60^{\mathrm{a}}$ & (10) \\
\hline Lateroventral central gray & 2.9 & (1.3) & 14 & (6.6) & $17^{\mathrm{a}}$ & (4.4) & $31^{\mathrm{a}}$ & (10) & $83^{\mathrm{b}}$ & (19) & $127^{\mathrm{c}}$ & (29) \\
\hline Cochlear nuclei $\dagger$ & 20 & $(6.0)$ & $73^{\mathrm{a}}$ & (13) & $116^{\mathrm{a}}$ & (39) & $212^{\mathrm{b}}$ & (49) & $377^{\mathrm{c}}$ & (54) & $561^{\mathrm{d}}$ & (41) \\
\hline Inferior colliculus cen/dor $\dagger$ & 290 & $(60)$ & $741^{\mathrm{a}}$ & (109) & $888^{\mathrm{a}}$ & $(90)$ & $1163^{\mathrm{a}}$ & (168) & $1405^{\mathrm{b}}$ & (39) & $1781^{\mathrm{c}}$ & (25) \\
\hline
\end{tabular}




\begin{tabular}{|c|c|c|c|c|c|c|c|c|c|c|c|c|}
\hline \multirow[b]{2}{*}{ Brain region } & \multicolumn{12}{|c|}{ Experimental group } \\
\hline & Naive & & $60 \mathrm{~dB}$ & & $70 \mathrm{~dB}$ & & $80 \mathrm{~dB}$ & & $90 \mathrm{~dB}$ & & $105 \mathrm{~dB}$ & \\
\hline Inferior colliculus external† & 56 & $(8.3)$ & 82 & $(18)$ & $171^{\mathrm{b}}$ & (19) & $212^{\mathrm{b}}$ & (19) & $387^{\mathrm{c}}$ & $(42)$ & $686^{\mathrm{d}}$ & $(55)$ \\
\hline Nuc lateral lemniscus $\dagger$ & 13 & (1.5) & 18 & (3.9) & $39^{\mathrm{b}}$ & (2.8) & $79^{\mathrm{b}}$ & $(9.2)$ & $171^{\mathrm{c}}$ & (58) & $480^{\mathrm{e}}$ & (15) \\
\hline Superior olivary complex $\dagger$ & 26 & $(2.4)$ & $63^{\mathrm{a}}$ & (11) & $108^{\mathrm{a}}$ & (6.1) & $147^{\mathrm{b}}$ & (22) & $281^{\mathrm{d}}$ & $(60)$ & $390^{\mathrm{d}}$ & (15) \\
\hline Locus coeruleust & 0.2 & (0) & $1.6^{\mathrm{a}}$ & $(0.3)$ & $1.6^{\mathrm{a}}$ & $(0.3)$ & $1.3^{\mathrm{a}}$ & $(0.2)$ & $3.6^{\mathrm{a}}$ & (1.5) & $6.9^{\mathrm{a}}$ & (2.1) \\
\hline Raphe dorsalt & 2.7 & $(0.8)$ & 8.8 & $(5.7)$ & 7.6 & (3.5) & 7.9 & (2.4) & $23^{\mathrm{a}}$ & $(5.0)$ & 16 & $(5.1)$ \\
\hline Raphe medial $\dagger$ & 2.0 & $(0.7)$ & $\begin{array}{l}0.0 \\
7.2\end{array}$ & (3.1) & $7.9^{\mathrm{a}}$ & (1.7) & 6.5 & (3.6) & $31^{\mathrm{d}}$ & (6.4) & $23^{\mathrm{a}}$ & (4.6) \\
\hline Superior colliculust $\dagger$ & 60 & (15) & $209^{a}$ & (59) & $293^{\mathrm{a}}$ & (71) & 123 & (27) & $527^{\mathrm{b}}$ & (100) & $294^{\mathrm{a}}$ & (16) \\
\hline Dorsal tegmental nuct & 4.3 & (2.1) & 18 & (4.7) & 22 & (11) & 15 & (5.7) & $28^{\mathrm{a}}$ & (4.3) & $29^{\mathrm{a}}$ & $(4.2)$ \\
\hline Laterodorsal teg nuc $\dagger$ & 1.9 & $(0.4)$ & 6.8 & $(2.0)$ & $14^{\mathrm{a}}$ & (5.6) & $10^{\mathrm{a}}$ & $(0.9)$ & $31^{\mathrm{b}}$ & (14) & $32^{\mathrm{b}}$ & $(4.7)$ \\
\hline Pedunculopontine teg nuc $\dagger$ & 5.9 & (1.1) & $28^{\mathrm{a}}$ & (5.9) & $31^{\mathrm{a}}$ & (3.2) & $32^{\mathrm{a}}$ & (7.3) & $90^{\mathrm{d}}$ & (27) & $63^{\mathrm{a}}$ & $(6.5)$ \\
\hline Ventral tegmental nuct & 6.7 & $(1.3)$ & 9.9 & $(2.0)$ & 14 & (3.5) & 16 & $(2.8)$ & $31^{\mathrm{b}}$ & $(7.0)$ & $26^{\mathrm{a}}$ & (1.1) \\
\hline Ventral tegmental area $\uparrow$ & 5.9 & $(2.9)$ & $51^{\mathrm{a}}$ & (17) & $46^{\mathrm{a}}$ & $(9.3)$ & $50^{\mathrm{a}}$ & (12) & $89^{\mathrm{a}}$ & (8.6) & $127^{\mathrm{a}}$ & (30) \\
\hline \multicolumn{13}{|l|}{ Cerebellum } \\
\hline Lobules $(1-10) \dagger$ & 117 & $(30)$ & $3586^{\mathrm{a}}$ & $(985)$ & $3750^{\mathrm{a}}$ & $(1362)$ & $1753^{\mathrm{a}}$ & (406) & $5026^{\mathrm{a}}$ & (1106) & $3259^{\mathrm{a}}$ & (646) \\
\hline Flocculus and paraflocculus & 58 & (16) & $876^{a}$ & (213) & $1426^{\mathrm{a}}$ & $(179)$ & $2370^{\mathrm{b}}$ & (180) & $2801^{\mathrm{b}}$ & (263) & $2046^{\mathrm{b}}$ & (169) \\
\hline
\end{tabular}

†One-way ANOVA $\mathrm{P} \leqslant 0.05$. Tukey Multiple Mean Comparisons: $\mathrm{P}<0.05$ vs Naive group ${ }^{\mathrm{a}}: \mathrm{P}<0.05$ vs Naive and $60 \mathrm{~dB}^{\mathrm{Groups}}{ }^{\mathrm{b}} ; \mathrm{P}<0.05$ vs Naive, 60 and $70 \mathrm{~dB}$ groups ${ }^{\mathrm{c}} ; \mathrm{P}<0.05$ vs Naive, 60,70 and $80 \mathrm{~dB}$ groups $^{\mathrm{d}} ; \mathrm{P}<0.05$ vs all other groups $\mathrm{e}^{\mathrm{e}}$.

repeatedly exposed (10 days total) to the same experimental environment ( $60 \mathrm{~dB}$ background noise condition). A quantitatively similar induction pattern was observed in rats exposed to moderate noise increments ( 10 and $20 \mathrm{~dB}$ above background, in the 70 and $80 \mathrm{~dB}$ conditions, respectively), with higher induction in some auditory-related structures of rats from the $80 \mathrm{~dB}$ condition. This wide regional c-fos induction in rats exhibiting mild or no corticosterone and behavioural stress responses is perhaps reflective of processes associated with exploration induced by transferring rats from their home cages to the experimental environment, differing in shape, sound, illumination and smell. Alternatively, it is possible that the transfer from the home cage to the experimental apparatus was still mildly stressful, producing corticosterone release that could have returned to low levels $60 \mathrm{~min}$ after the transfer. Such a mild stress might have induced feedback inhibition that prevented corticosterone release to moderate noise intensities. Either way, this wide regional c-fos induction was not specific to audiogenic stress, and it is therefore possible that some of the c-fos induction previously reported with other stress conditions (both physical or psychological), particularly in the amygdala, thalamus and cortex, was also evoked nonspecifically, even in animals repeatedly exposed to the experimental environment $(1,7,9-11,13,14,25)$. Because of this, it cannot be ruled out that some of the regional c-fos activation obtained by simply transferring rats in the experimental cage might have masked their specific involvement in audiogenic stress. The lack of difference in c-fos induction between rats displaying longer sleep duration compared to the lower auditory stimulation condition ( $60 \mathrm{~dB}$ background ) might be explained by the delayed latency for this behaviour to occur in the session, which might have precluded the observation of peak induction of c-fos mRNA at the time of sacrifice (less than $30 \mathrm{~min}$ ) associated with this specific behaviour.

c-fos induction above and beyond that obtained in the moderate noise conditions was observed in some brain regions of rats exposed to the loudest noise intensities ( 90 and $105 \mathrm{~dB}$ ). The bed nucleus of the stria terminalis, especially its medial and ventral nuclei, the septohypothalamic nucleus, the ventral portion of the dentate gyrus, a number of hypothalamic nuclei including the lateral preoptic area, the medial preoptic nucleus and the paraventricular nucleus, the median raphe and the pedunculopontine tegmental nucleus showed particularly strong c-fos induction in one or both stressed groups. These regions can therefore be proposed to be part of a specific brain circuit involved in some aspects of stress responsiveness to loud auditory stimulation. In fact, a general role of some hypothalamic regions (besides the paraventricular nucleus), the bed nucleus of the stria terminalis, the septohypothalamic/ventral lateral septal area and the raphe in stress responsiveness is suggested because these regions exhibit c-fos induction in response to other stimuli including hypertonic saline, swim and restraint $(4,11,12,14,26)$. Activation of the pedunculopontine tegmental nucleus and the ventral dentate gyrus has not been reported with other types of stimuli, and might therefore be specific to audiogenic stress.

The first aspect of stress responsiveness to loud auditory stimulation is the reception and transmission of the acoustic signal, which was clearly exhibited by the relationship obtained between noise intensity and c-fos induction in a number of auditory structures. c-fos induction in auditory nuclei appears to be specific to audiogenic stress, as activation of these regions has not been reported with other stressors. Although no attempts were made to determine precisely the auditory subnuclei activated with increasing noise intensities, the associated and unaligned sensory nuclei as compared to the main sensory nuclei of the auditory pathway appeared selectively active with the louder noises, as indicated by the reliably higher c-fos induction in the external nucleus of the inferior colliculus and the medial division of the medial geniculate body (27). The unreliable noise intensity relationship observed in the ventral/dorsal divisions of the medial geniculate body and auditory cortex might be related to a higher percentage of cells displaying non-monotonicity of rate/intensity level functions in these areas, compared to structures in the lower auditory system (28).

On the other hand, a major component involved in stress responsiveness to loud noise stimulation was the neuroendocrine (corticosterone) response which was directly associated with 


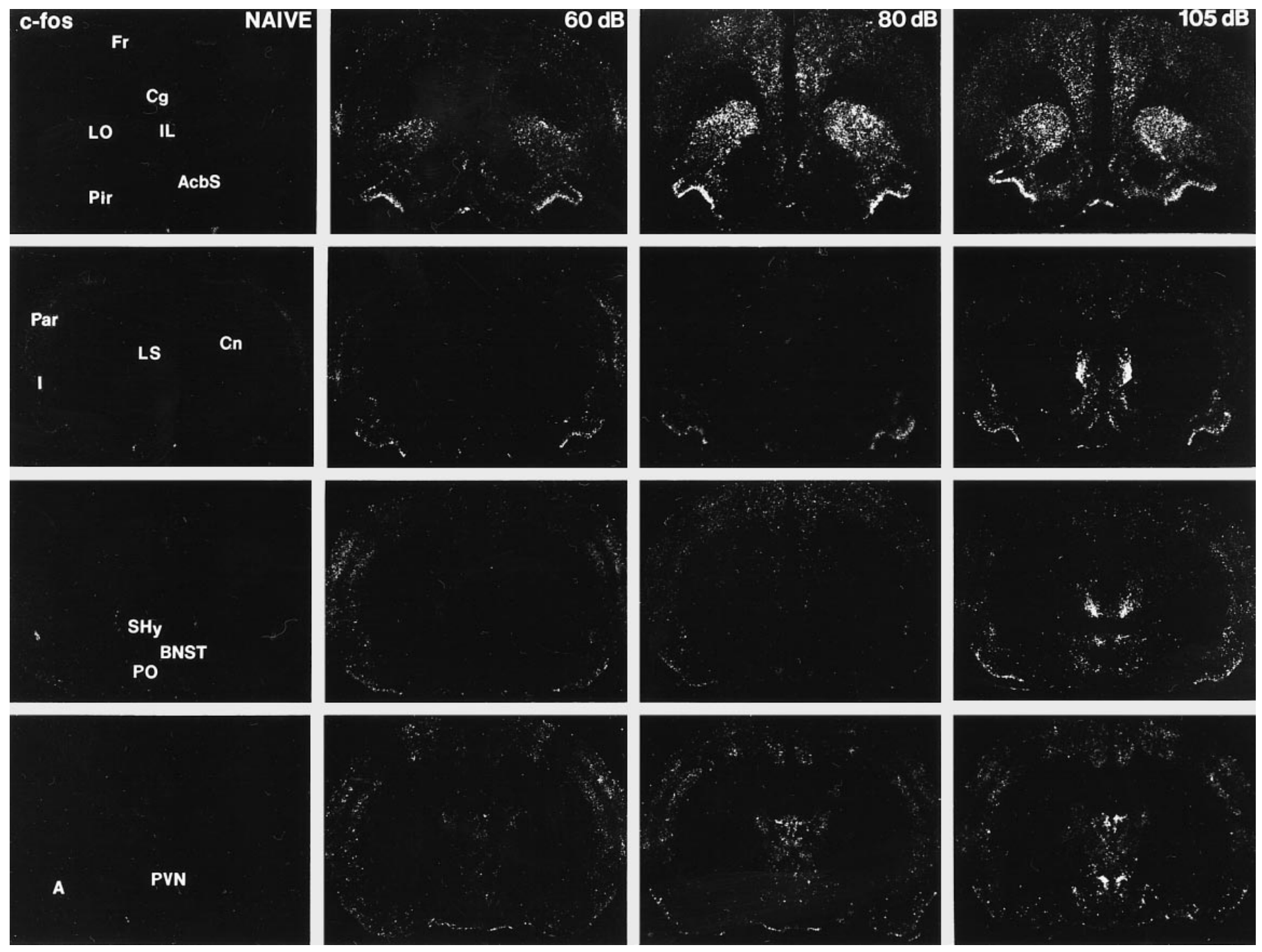

FIG. 3. Photomicrographs from x-ray films exposed for five days following in situ hybridization with an antisense cRNA probe against c-fos mRNA. Animal brain sections from Naive, 60,80, or $105 \mathrm{~dB}$ conditions are represented at four different levels in the forebrain and diencephalon. Intense c-fos induction is observed in the bed nucleus of the stria terminalis (BNST), ventral lateral septum (LS), septohypothalamic nucleus (SHy), preoptic area (PO), and paraventricular hypothalamic nucleus (PVN) of rats in the $105 \mathrm{~dB}$ condition. Other abbreviations: A, amygdala; AcbS, accumbens, shell; $\mathrm{Cg}$, cingulate cortex; Cn, caudate nucleus; Fr, frontal cortex; I, insular cortex; IL, infralimbic cortex; LO, lateralorbital cortex; Par, parietal cortex; Pir, piriform cortex.

strong c-fos induction in the parvocellular region of the paraventricular nucleus of the hypothalamus in rats exposed to the two higher noise intensities. Neurons of the parvocellular region contain corticotropin-releasing hormone and form the origin of the 'final common path' for activation of the hypothalamopituitary-adrenal axis, ultimately responsible for the release of corticosteroids by the adrenal cortex $(29,30)$. Induction of c-fos in the paraventricular nucleus is common to most stressors studied (4-7, 9-12, 14, 26).

Because no direct projections have been reported from auditory structures to the hypothalamic paraventricular nucleus, additional relays are required to activate $\mathrm{CRH}$ paraventricular neurons by audiogenic stress. Activated structures, particularly those of the hypothalamus (medial preoptic nucleus, lateral preoptic area and supramammillary nucleus) and the anterior bed nucleus of the stria terminalis are known to have direct projections to the parvocellular region of the paraventricular nucleus $(26,31-35)$, and are thus in a position to relay signals initiated by loud noise stimulation. In turn, the septohypothalamic nucleus and closely associated ventral lateral septum project to some of the same hypothalamic (preoptic and supramammillary nuclei) and stria terminalis areas which directly innervate the paraventricular nucleus (36). By far the heaviest projections to the anterior bed nucleus of the stria terminalis and the ventral lateral septum are from various divisions of the amygdala $(36,37)$. Generally, activation of the amygdala was moderate in all noise conditions, but the lateral nucleus of the amygdala showed significant c-fos induction in the $105 \mathrm{~dB}$ condition (with a trend in the $90 \mathrm{~dB}$ condition, $\mathrm{P}=0.08$ ) compared to the $60 \mathrm{~dB}$ background noise condition. The lateral nucleus projects to several basolateral and medial amygdaloid nuclei $(38,39)$, and is in turn innervated by the medial division of the medial geniculate nucleus $(40,41)$, the last auditory structure to show reliable c-fos induction in the stressed groups of the present study. Recently, we found that 

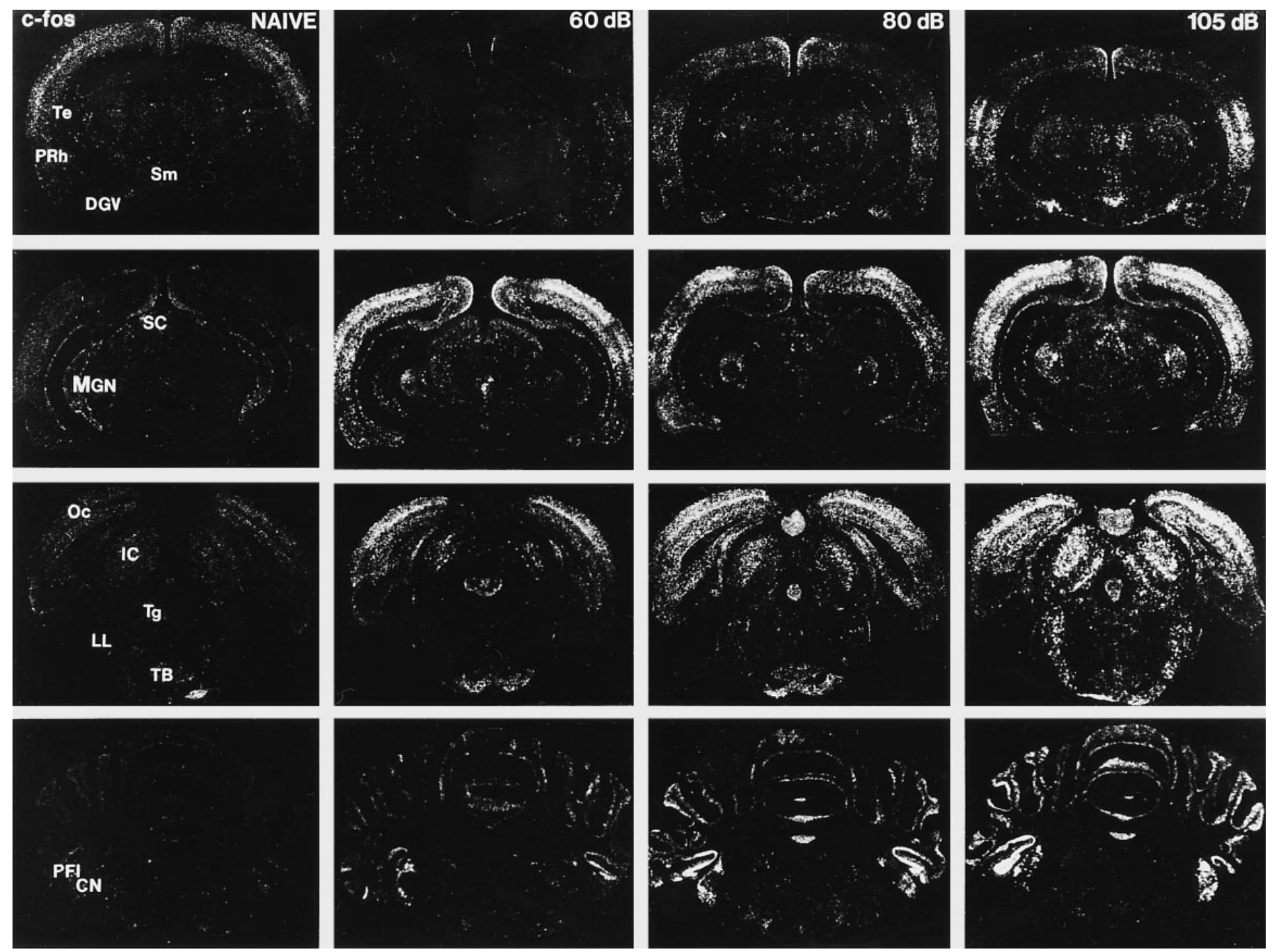

FIG. 4. Photomicrographs from x-ray films exposed for five days following in situ hybridization with an antisense cRNA probe against c-fos mRNA. Animal brain sections from Naive, 60,80 , or $105 \mathrm{~dB}$ conditions are represented at midbrain, pons and brainstem levels. c-fos induction was particularly strong and consistent in the ventral dentate gyrus (DGV), supramammillary nucleus (Sm), medial geniculate nucleus (MGN), inferior colliculus (IC), nuclei of the lateral lemniscus (LL), tegmental nuclei (Tg) and the cochlear nuclei (CN). Other abbreviations: Oc, occipital (visual) cortex; PFl, cerebellar flocculus and paraflocculus; PRh, perirhinal cortex; SC, superior colliculus; TB, trapezoid bodies; Te, auditory cortex.

neurotoxic lesions aimed at the lateral nucleus of the amygdala significantly attenuated the behavioural and neuroendocrine responses to audiogenic stress (Campeau and Watson, unpublished observations). Thus, although incomplete, the data suggest that the lateral nucleus of the amygdala might act as an interface between the auditory system and the stress responsive areas of the lateral septum and bed nucleus of the stria terminalis. The difficulty to discern clearly between different subnuclei of the medial and basolateral nuclei of the amygdala might have precluded the finding of reliable induction in some of these areas. A diagram of a putative circuit associated with audiogenic stress responsiveness is presented in Fig. 8 .

Interactions of brainstem and pontine auditory areas with other brainstem regions (raphe, pedunculopontine tegmental area or other areas not investigated in the present study) could play an important role by directly innervating hypothalamic, bed nucleus of the stria terminalis or lateral septal areas. However, the results of recent studies showing complete abolition of corticosterone release specifically to audiogenic stress by complete auditory thalamic lesions (42), makes this possibility unlikely. It is possible that the activation observed in the tegmental nuclei (pedunculopontine, laterodorsal) and the lateroventral central gray is associated with the behavioural outcome of audiogenic stress. Clearly, additional studies, including lesion or inactivation procedures, will be required to determine more precisely the role of the stress responsive areas found in the present study in the neuroendocrine and behavioural responses evoked by audiogenic stress.

\section{Materials and methods}

Subjects

Twenty-four naive male albino Sprague-Dawley rats weighing 250-300 gm (Charles River Co., Kingston, NY, USA) were used. They were housed in plastic cages $(20 \times 25 \times 50 \mathrm{~cm})$ in groups of 2 with water and laboratory chow continuously available. All rats were maintained on a $12 \mathrm{~h}: 12 \mathrm{~h}$ 
584 Audiogenic stress and c-fos induction

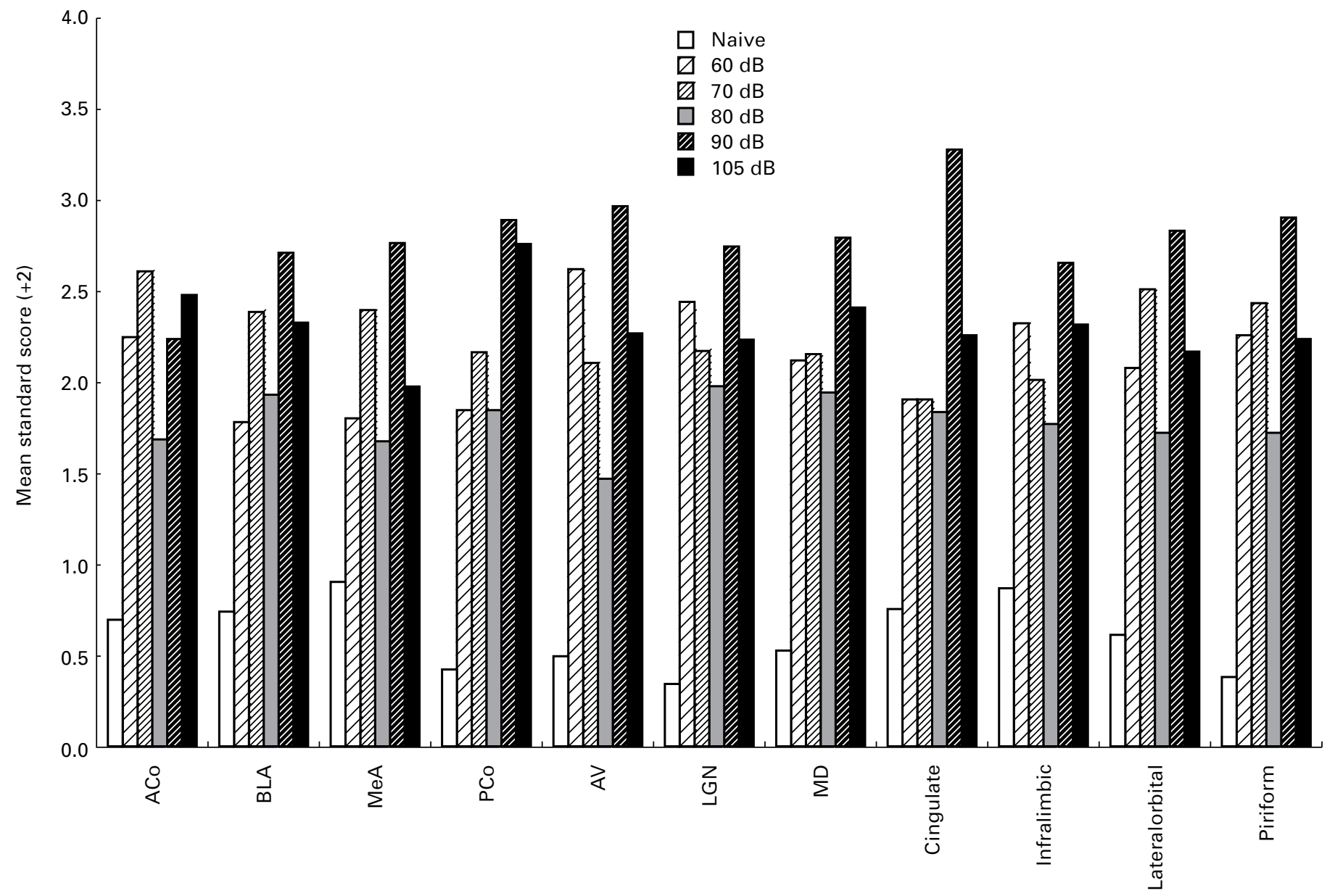

Brain area

FIG. 5. Standardized c-fos induction in some amygdaloid, thalamic and cortical structures which was higher in all conditions compared to Naive, but not different from each other. Mean c-fos integrated densities were transformed to standard scores and 2 was added to all means to obtain positive values (all standard deviations have units of one). Abbreviations: ACo, anterior cortical nucleus of the amygdala; AV, anteroventral thalamic nucleus; BLA, basolateral nucleus of the amygdala; LGN, lateral geniculate nucleus; MD, mediodorsal thalamic nucleus; MeA, medial nucleus of the amygdala; PCo, posterior cortical nucleus of the amygdala.

light-dark cycle (lights on at 7.00) and acclimated to the colony rooms for a week before the experiments began. The background noise level in the quiet animal colony was $\approx 50 \mathrm{~dB}(\mathrm{~A})$. All procedures were carried out between 7.00 and 13.00 .

\section{Apparatus}

The two experimental cages were identical $20 \times 25 \times 30 \mathrm{~cm}$ Plexiglas boxes with stainless steel rod floors $(2 \mathrm{~mm}$ bars spaced $1.2 \mathrm{~cm}$ apart, centre to centre). The boxes were enclosed into a ventilated, dimly lit $(20 \mathrm{~W}$ incandescent bulb), sound attenuating LeHigh Valley chamber $(53 \times 56 \times 96 \mathrm{~cm})$. White noise $(0-20 \mathrm{kHz})$ was delivered through a Grass AM7 Audio Monitor speaker, which was placed in between, and adjacent to the two boxes. The noise was produced by a General Radio RandomNoise Generator (Type 1390-A). Noise intensity was measured by placing a Radio Shack Realistic Sound Level Meter (A scale; no. 33-2050) in the boxes with the lid closed. The noise level provided by the LeHigh Valley chamber's fan and the white noise generator was $\approx 60 \mathrm{~dB}$, which will be referred here as the background noise level of the experimental cages.

\section{Behavioural procedures}

The rats were handled for 3 to $4 \mathrm{~min}$ and placed in the experimental cages for 10 min daily for 9 consecutive days. Twenty-four or $48 \mathrm{~h}$ later, the rats were placed in the experimental boxes for $60 \mathrm{~min}$. For the last $30 \mathrm{~min}$, white noise of either $60 \mathrm{~dB}$ ( background noise; no change), $70 \mathrm{~dB}$,
$80 \mathrm{~dB}, 90 \mathrm{~dB}$, or $105 \mathrm{~dB}$ were presented to different groups of rats $(\mathrm{n}=$ 4/group). During the $30 \mathrm{~min}$ white noise presentation, the behaviour of all rats was scored every $10 \mathrm{~s}$ in one of the following 5 categories: immobility (freezing posture or sitting posture with head up and no detectable movement except for breathing), grooming, locomoting, rearing, and sleeping (characteristic curled position with tail under body and head on the floor). The rats were then immediately decapitated following noise exposure, trunk blood was collected and the brains were rapidly removed and frozen in chilled isopentane $\left(-40^{\circ} \mathrm{C}\right)$. Four rats that were not handled or exposed to the experimental boxes served as naive controls and were decapitated immediately upon removal from the colony room.

\section{Corticosterone radioimmunoassay}

Upon decapitation, trunk blood was collected into ice chilled tubes containing EDTA. Blood samples were centrifuged at $1500 \mathrm{~g}$ for $10 \mathrm{~min}$, the plasma was pipetted into $0.5 \mathrm{ml}$ Ependorf microcentrifuge tubes, and stored at $-20{ }^{\circ} \mathrm{C}$ until assayed.

Corticosterone was measured by radioimmunoassay using a specific rabbit antibody raised in our laboratory, with less than 3\% crossreactivity with other steroids, including cortisol, deoxycorticosterone, aldosterone, testosterone and progesterone (Dr Dana Helmreich, personal communication). Plasma samples were diluted $1: 100$ in $0.05 \mathrm{M}$ sodium phosphate buffer containing $0.25 \%$ bovine serum albumin (BSA) $\mathrm{pH} 7.4$, and corticosterone separated from binding protein by heat $\left(70^{\circ} \mathrm{C}, 30 \mathrm{~min}\right)$. 


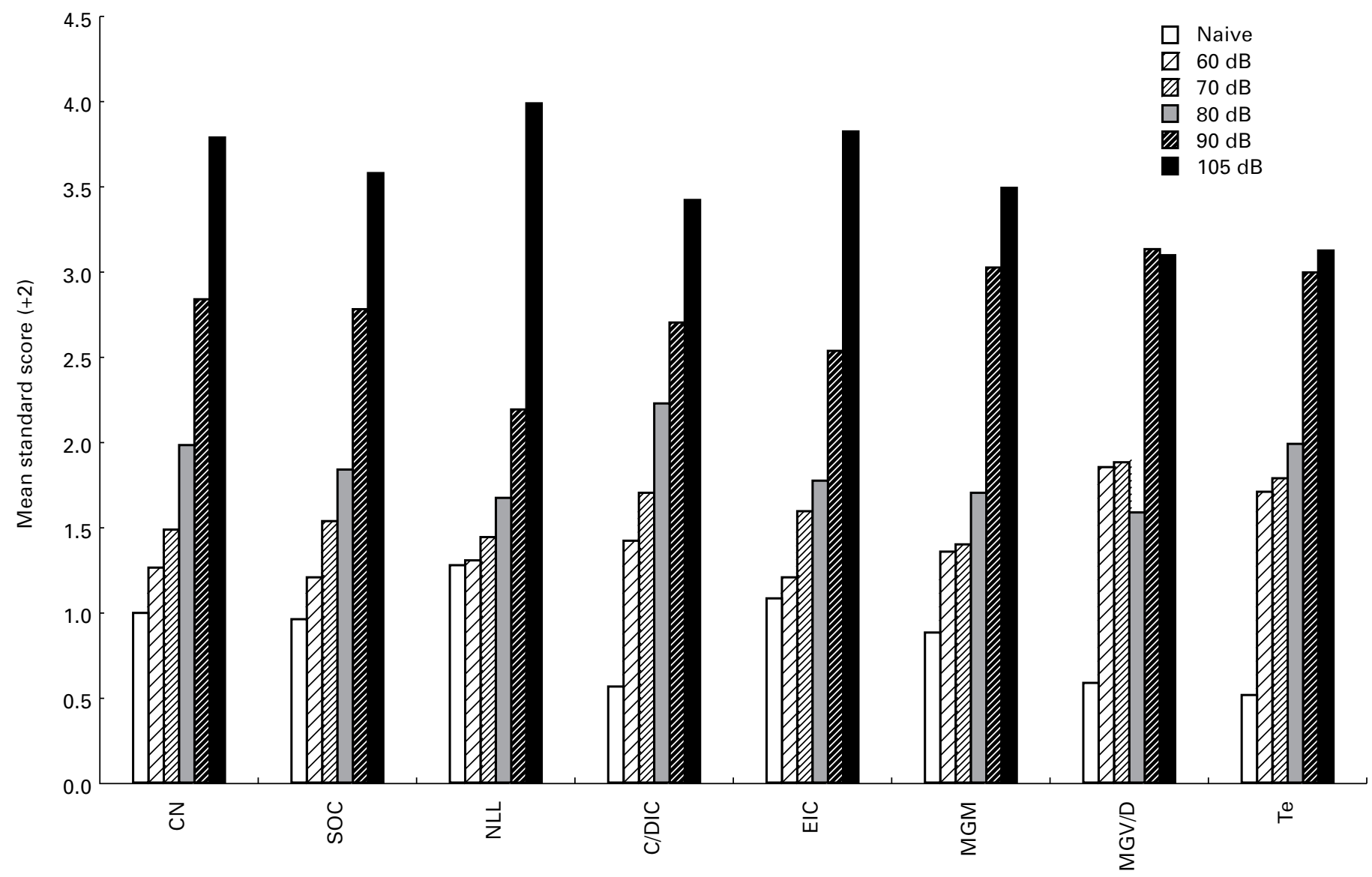

Brain area

FIG. 6. Standardized c-fos induction show an intensity dependent c-fos induction in many auditory regions. Mean integrated c-fos densities were transformed to standard scores and 2 was added to all means to obtain positive values (all standard deviations have units of one). Abbreviations: $\mathrm{CN}$, cochlear nuclei; C/DIC, central/dorsal nuclei of the inferior colliculus; EIC, external nucleus of the inferior colliculus; MGM, medial division of the medial geniculate nucleus; MGV/D, ventral and dorsal divisions of the medial geniculate nucleus; NLL, nuclei of the lateral lemniscus; SOC, superior olivary complex; Te, auditory cortex.

Duplicate samples of $200 \mu 1$ to which $50 \mu 1$ of trace $\left({ }^{3} \mathrm{H}\right.$-corticosterone; Amersham $50 \mathrm{Ci} / \mathrm{mmol}, 10,000 \mathrm{cpm} /$ tube) and $50 \mu \mathrm{l}$ of antibody (final concentration $1: 12800$ ) were incubated at $4{ }^{\circ} \mathrm{C}$ overnight. Separation of bound from free corticosterone was achieved by adding $0.5 \mathrm{ml}$ of chilled $1 \%$ charcoal- $0.1 \%$ dextran mixture in buffer for 10 min at $4{ }^{\circ} \mathrm{C}$ and centrifuged for $10 \mathrm{~min}$ at $3000 \mathrm{rpm}$. (Sorvall RC-5B). The supernatant was poured into $4 \mathrm{ml}$ scintillation fluid and bound ${ }^{3} \mathrm{H}$-corticosterone counted on a Packard CA2000 liquid scintillation analyzer and compared to a standard curve (range: $0-80 \mu \mathrm{g} / \mathrm{dl}$ ). All samples were measured simultaneously to reduce interassay variability; within assay variability was less than $5 \%$.

\section{In situ hybridization histochemistry}

After rapid decapitation, brains were removed and frozen in isopentane chilled to $-40^{\circ}$ to $-50^{\circ} \mathrm{C}$, and stored at $-80^{\circ} \mathrm{C}$. Ten micron sections were then cut on a Bright cryostat, thaw mounted onto polylysine coated slides, and stored at $-80^{\circ} \mathrm{C}$ until further processed. Slides were fixed in a buffered $4 \%$ paraformaldehyde solution for $1 \mathrm{~h}$. Tissue sections were then deproteinated with Proteinase $\mathrm{K}(1.0 \mu \mathrm{g} / \mathrm{ml})$ for $10 \mathrm{~min}$ at $37^{\circ} \mathrm{C}$. The slides were then rinsed in $\mathrm{H}_{2} \mathrm{O}$ for $5 \mathrm{~min}$, acetylated in $0.1 \mathrm{~m}$ triethanolamine containing $0.25 \%$ acetic anhydride for $10 \mathrm{~min}$, rinsed for an additional $5 \mathrm{~min}$ in $\mathrm{H}_{2} \mathrm{O}$, and dehydrated in a progressive series of alcohols.

${ }^{35} \mathrm{~S}$-labelled cRNA probes were generated for c-fos from cDNA subclones in transcription vectors using standard in vitro transcription methodology. The rat c-fos cDNA clone (courtesy of Dr T. Curran) was subcloned in pGem3Z (courtesy of Dr C. A. Fox) and cut with HindIII to yield a $680 \mathrm{nt}$ cRNA probe. Riboprobes were labelled in a reaction mixture consisting of $1 \mu \mathrm{g}$ linearized plasmid, $1 \mathrm{X}$ T7 or SP6 transcription buffer (BRL), $125 \mu \mathrm{Ci}{ }^{35} \mathrm{~S}$-UTP, $150 \mu \mathrm{M}$ NTPs-UTP, $12.5 \mathrm{~mm}$ dithiothreitol, $20 \mathrm{U}$ RNase inhibitor, and $6 \mathrm{U}$ polymerase. The reaction was allowed to proceed for $120 \mathrm{~min}$ at $37^{\circ} \mathrm{C}$, and probe was separated from free nucleotides over a Sephadex G50-50 column. Riboprobes were diluted in hybridization buffer to yield $\approx 1.5 \times 10^{6} \mathrm{dpm} / 30 \mu \mathrm{l}$ buffer. The hybridization buffer consisted of $50 \%$ formamide, $10 \%$ dextran sulfate, $3 \times \mathrm{SSC}, 50 \mathrm{~mm}$ sodium phosphate buffer $(\mathrm{pH}=7.4)$, 1X Denhardt's solution, and $0.1 \mathrm{mg} / \mathrm{ml}$ yeast tRNA. Diluted probe $(30 \mu \mathrm{l})$ was applied to each slide and sections were coverslipped. Slides were placed in sealed plastic boxes lined with filter paper moistened with $50 \%$ formamide in $50 \mathrm{~mm}$ sodium phosphate buffer, and were subsequently incubated for $12 \mathrm{~h}$ at $55^{\circ} \mathrm{C}$. Coverslips were then removed, and slides were rinsed several times in $2 \times \mathrm{SSC}$. Slides were then incubated in RNase A $(200 \mu \mathrm{g} / \mathrm{ml})$ for $60 \mathrm{~min}$. at $37^{\circ} \mathrm{C}$, washed successively in $2 \mathrm{X}, 1 \mathrm{X}, 0.5 \mathrm{X}$ and $0.1 \times \mathrm{SSC}$ for $5-10 \mathrm{~min}$ each, and washed in $0.1 \times \mathrm{SSC}$ for $60 \mathrm{~min}$. at $65^{\circ} \mathrm{C}$. Slides were subsequently rinsed in fresh $0.1 \times \mathrm{SSC}$, dehydrated in a graded series of alcohols, and exposed to Kodak XAR X-ray film.

Control experiments were performed on tissue sections pre-treated with RNase A $\left(200 \mu \mathrm{g} / \mathrm{ml}\right.$ at $37^{\circ} \mathrm{C}$ for $60 \mathrm{~min}$.) prior to hybridization; this treatment prevented labelling. Alternatively, some control sections were hybridized with the sense cRNA strands, which in all cases did not lead to significant hybridization to tissue sections.

Importantly, three to five slides for a given brain region from each rat 


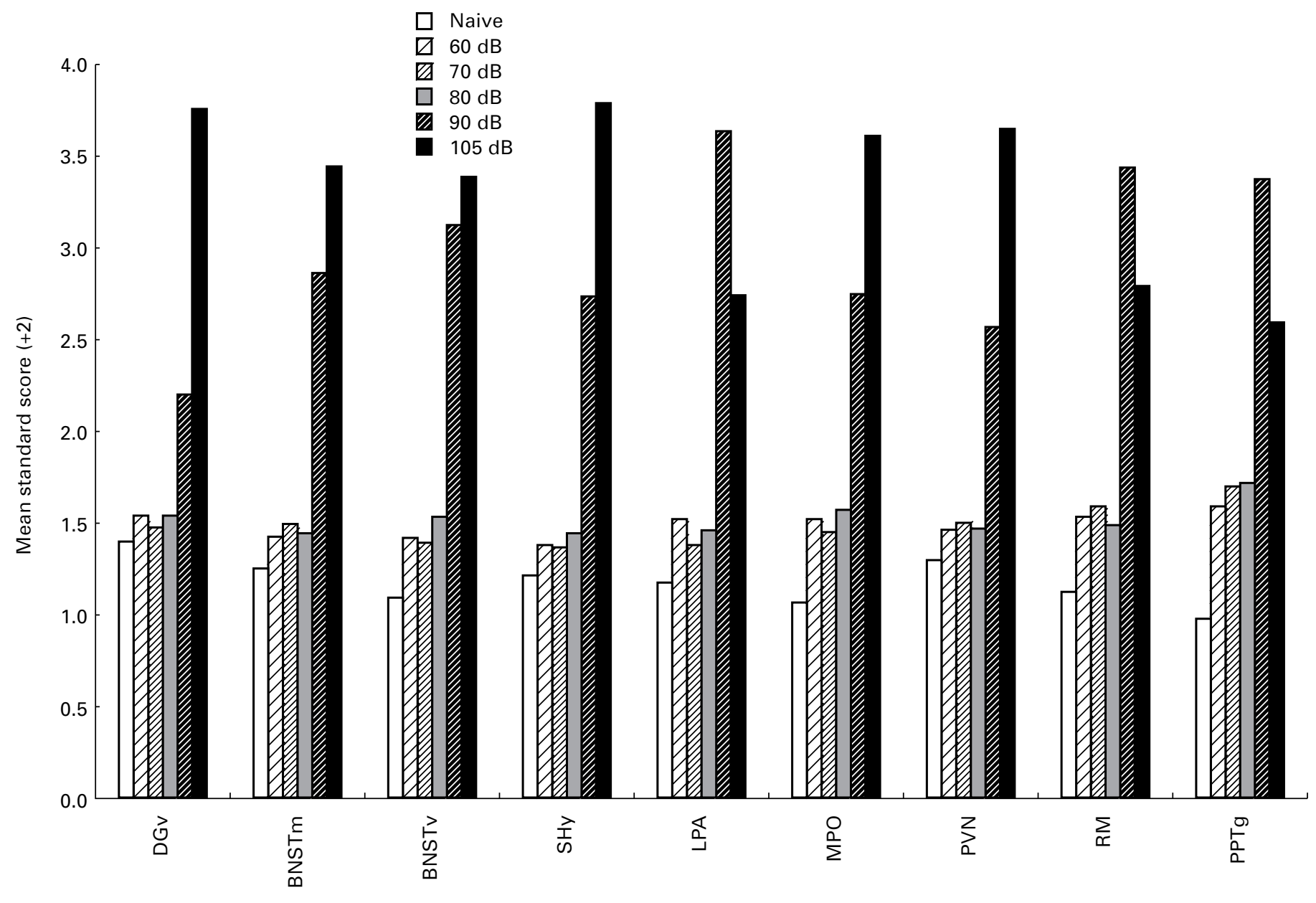

Brain area

FIG. 7. Standardized c- $f o s$ induction in regions where the 90 and/or $105 \mathrm{~dB}$ conditions produced reliable induction compared to all other conditions. Mean integrated c-fos densities were transformed to standard scores and 2 was added to all means to obtain positive values (all standard deviations have units of one). Abbreviations: BNSTm, medial nucleus of the bed nucleus of the stria terminalis; BNSTv, ventral nucleus of the bed nucleus of the stria terminalis; DGv, ventral dentate gyrus; LPA, lateral preoptic area; MPO, medial preoptic nucleus; PPTg, pedunculopontine tegmental nucleus; PVN, paraventricular nucleus of the hypothalamus; RM, median raphe; SHy, septohypothalamic nucleus.

included in the study were processed simultaneously to allow direct comparisons in the same regions. Multiple in situ hybridizations were thus performed at different levels of the brain with all animals represented to reduce the effects of technical variations within regions. Sections of all rats in the same region were all exposed on the same $\mathrm{x}$-ray film to further minimize variations. Semi-quantitative analyses were performed on digitized images from $\mathrm{x}$-ray films in the linear range of the gray values obtained from our acquisition system (Northern Light lightbox model B 95, a Pulnix TV camera model TM-745 fitted with a Nikkor $55 \mathrm{~mm}$ lens, connected to an A/D converter onboard a Macintosh Quadra 840AV, captured with NIH Image v1.59). Signal pixels of a region of interest were defined as being 3.5 standard deviations above the mean of a cell poor area close to the region of interest. The number of pixels and the average pixel values above the set background were then computed for each regions of interest, and multiplied, giving an integrated densitometric measure. An average of 4 to 6 measurements were made on different sections, for each region of interest, and these values were further averaged to get a single integrated density value per region for each rat. Slides undergoing in situ hybridization were stained with cresyl violet and used extensively in the determination of regional boundaries on the digitized images.

\section{Statistics}

Repeated measures analysis of variance (ANOVA) was performed on the means of each behavioural categories in separate 5-min periods.
Additional one-way ANOVAs were performed at each time period if an overall Condition or Condition $\times$ Time period effect were initially detected, to determine more precisely the source of significant effects, with Tukey's multiple mean comparisons following significant ANOVAs. One-way ANOVA was performed on plasma corticosterone levels, followed by a Tukey multiple mean comparison test to determine the source of significant effects.

For purposes of statistical analysis, the mean c-fos integrated density values were transformed to natural logarithm values to reduce between group variances observed in some regions. One-way ANOVAs were performed on the transformed mean integrated densities obtained from each region where c-fos mRNA induction was measured. This was followed by Tukey's post-hoc multiple mean comparisons to determine more exactly the source of the differences obtained with the initial ANOVA. Statistical significance in all instances was set to $\mathrm{P}=0.05$.

\section{Acknowledgements}

This research was supported by NIMH Grant MH-42251 (S.J.W.), and a Postdoctoral Fellowship from the Medical Research Council of Canada (S.C). Thanks are extended to Dr Heidi E.W. Day for critical comments on an earlier draft of this manuscript.

Accepted 21 January 1997 


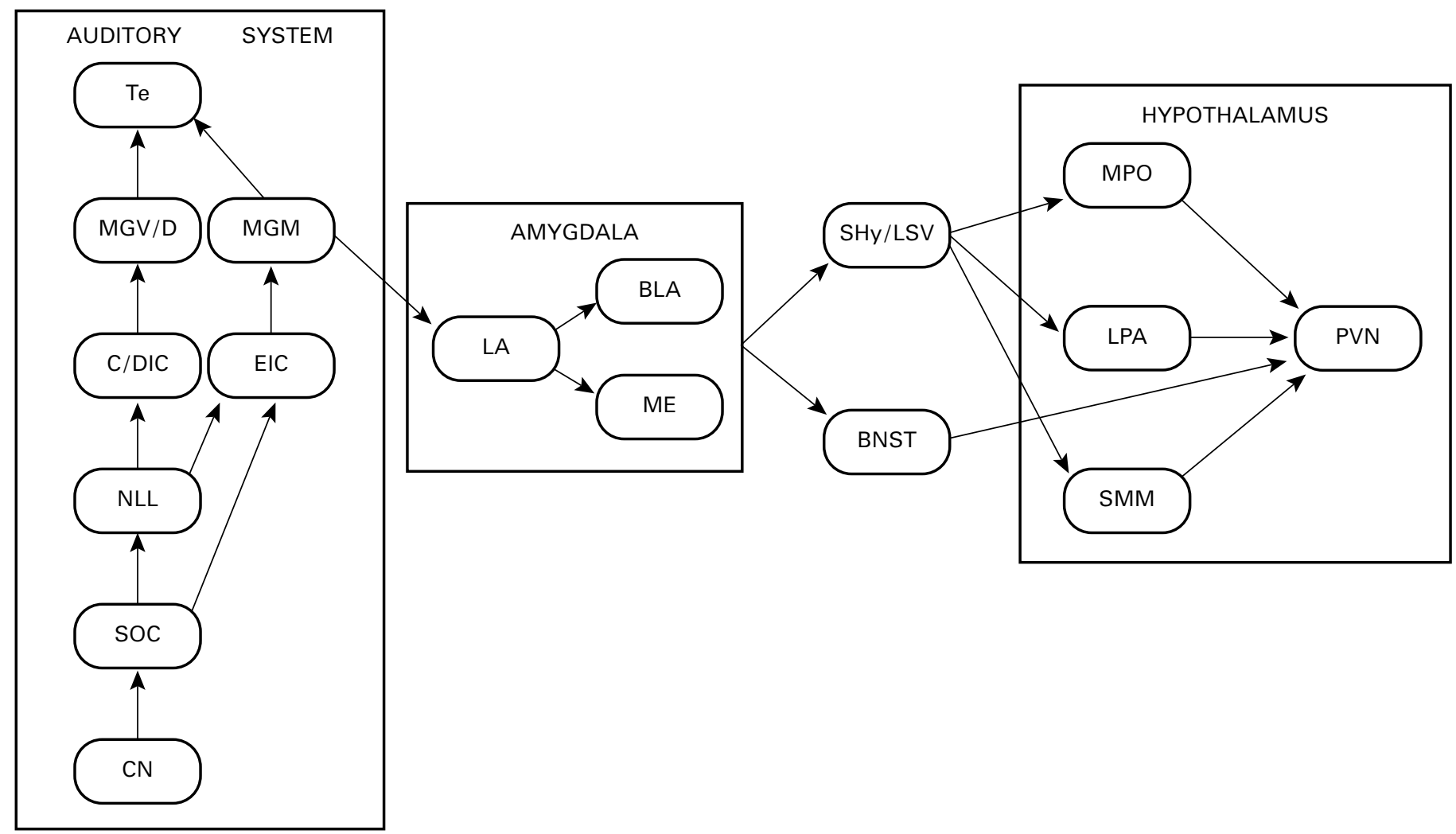

FIG. 8. Schematic diagram of a putative circuit involved in activation of $\mathrm{CRH}$ containing neurons of the paraventricular hypothalamic nucleus by audiogenic stress. Arrows indicate known projections between the various areas illustrated, but are not exclusive. Abbreviations: Auditory system, CN, cochlear nuclei; SOC, superior olivary complex; NLL, nuclei of the lateral lemniscus; C/DIC, central/dorsal nuclei of the inferior colliculus; EIC, external nucleus of the inferior colliculus; MGV/D, ventral and dorsal divisions of the medial geniculate body; MGM, medial division of the medial geniculate body; Te, auditory cortex; Amygdala, LA, lateral nucleus; BLA, basolateral nucleus; ME, medial nucleus; BNST, bed nucleus of the stria terminalis; SHy/LSV, septohypothalamic nucleus/ventral lateral septum; Hypothalamus, MPO, medial preoptic nucleus; LPA, lateral preoptic area; SMM, supramammillary nucleus; PVN, paraventricular nucleus.

\section{References}

1 Beck CHM, Fibiger HC. Conditioned fear-induced changes in behavior and in the expression of the immediate early gene c-fos: With and without diazepam pretreatment. J Neurosci 1995; 15: 709-720.

2 Campeau S, Hayward M, Hope B et al. Induction of the c-fos protooncogene in the rat amygdala during unconditioned and conditioned fear. Brain Res 1991; 565: 349-352.

3 Schreiber SS, Tocco G, Shors TJ et al. Activation of immediate early genes after acute stress. NeuroReport 1991; 2: 17-20.

4 Sharp F, Sagar S, Hicks K et al. c-fos mRNA, Fos and Fos-related antigen induction by hypertonic saline and stress. J Neurosci 1991; 11: $2321-2331$

5 Arnold F, De Lucas Bueno M, Shiers H et al. Expression of c-fos in regions of the basal limbic forebrain following intracerebroventricular corticotropin-releasing factor in unstressed and stressed male rats. Neuroscience 1992; 51: 377-390.

6 Smith MA, Banerjee S, Gold PW et al. Induction of c-fos mRNA in rat brain by conditioned and unconditioned stressors. Brain Res 1992; 578: 135-141.

7 Pezzone M, Lee W-S, Hoffman G et al. Induction of c-Fos immunoreactivity in the rat forebrain by conditioned and unconditioned aversive stimuli. Brain Res 1992; 597: 41-50.

8 Pezzone M, Lee W-S, Hoffman G et al. Activation of brainstem catecholaminergic neurons by conditioned and unconditioned aversive stimuli as revealed by c-Fos immunoreactivity. Brain Res 1993; 608: $310-318$

9 Senba E, Matsunaga K, Tohyama M et al. Stress-induced c-fos expression in the rat brain: activation mechanism of sympathetic pathway. Brain Res Bull 1993; 31: 329-344.

10 Duncan G, Johnson K, Breese G. Topographic patterns of brain activity in response to swim stress: assesment by 2-deoxyglucose uptake and expression of Fos-like immunoreactivity. J Neurosci 1993; 13: $3932-3943$.

11 Duncan G, Knapp D, Breese G. Neuroanatomical characterization of Fos induction in rat behavioral models of anxiety. Brain Res 1996; 713: 79-91.

12 Bonaz B, Tache Y. Induction of Fos immunoreactivity in the rat brain after cold- restraint induced gastric lesions and fecal excretion. Brain Res 1994; 652: 56-64.

13 Melia KR, Ryabinin AE, Schroeder R et al. Induction and habituation of immediate early gene expression in rat brain by acute and repeated restraint stress. J Neurosci 1994; 14: 5929-5938.

14 Cullinan WE, Herman JP, Battaglia DF et al Pattern and time course of immediate early gene expression in rat brain following acute stress. Neuroscience 1995; 64: 477-505.

15 Henkin RI, Knigge KM. Effect of sound on the hypothalamicpituitary-adrenal axis. Am J Physiol 1963; 204: 910-914.

16 Collu R, Jequier JC. Pituitary response to auditory stress: Effects of treatment with a-methyl-p-tyrosine. Usefulness of a factorial mixed design for statistical analysis. Can J Physiol Pharmacol 1976; 54: 596-602.

17 Borrell J, Torrellas A, Guaza C et al. Sound stimulation and its effects on the pituitary-adrenocortical function and brain catecholamines in rats. Neuroendocrinology 1980; 31: 53-59.

18 Armario A, Castellanos J, Balasch J. Adaptation of anterior pituitary hormones to chronic noise stress in male rats. Behav Neural Biol 1984; 41: 71-76. 
588 Audiogenic stress and c-fos induction

19 Irwin MR, Segal DS, Hauger RL et al. Individual behavioral and neuroendocrine differences in responsiveness to audiogenic stress. Pharmacol Biochem Behav 1989; 32: 913-917.

20 Segal DS, Kuczenski R, Swick D. Audiogenic stress response: behavioral characteristics and underlying monoamine mechanisms. J Neural Transm 1989; 75: 31-50.

21 Britton KT, Segal DS, Kuczenski R et al. Dissociation between in vivo hippocampal norepinephrine response and behavioral/neuroendocrine responses to noise stress in rats. Brain Res 1992; 574: $125-130$.

22 Spencer JAD, Moran DJ, Lee A et al. White noise and sleep induction. Arch Dis Child 1990; 65: 135-137.

23 Arankowsky-Sandoval G, Stone WS, Gold PE. Enhancement of REM sleep with auditory stimulation in young and old rats. Brain Res 1992; 589: 353-357.

24 Kawada T, Suzuki S. Sleep induction effects of steady $60 \mathrm{~dB}$ (A) pink noise. Ind Health 1993; 31: 35-38.

25 Smith C, Hauser E, Renaud $\mathrm{N}$ et al. Increased hypothalamic $[3 \mathrm{H}]$ flunitrazepam binding in hypothalamic-pituitary-adrenal axis hyporesponsive Lewis rats. Brain Res 1992; 569: 295-299.

26 Cullinan W, Helmreich D, Watson S. Fos expression in forebrain afferents to the hypothalamic paraventricular nucleus following swim stress. J Comp Neurol 1996; 368: 88-99.

27 Winer JA, Morest DK. The medial division of the medial geniculate body of the cat: Implications for thalamic organization. $J$ Neurosci 1983; 3: 2629-2651.

28 Aitkin L. The Auditory Cortex: Structural and functional bases of auditory perception. London: Chapman and Hall, 1990.

29 Sawchenko PE. The final common path: Issues concerning the organization of central mechanisms controlling corticotropin secretion. In: Brown M, Koob G, Rivier C, eds. Stress Neurobiology and Neuroendocrinology New York: Marcel Dekker, 1991 $55-71$.

30 Akil H, Morano M. Stress. In: Bloom F, Kupfer D, eds. Psychopharmacology: The Fourth Generation of Progress. New York: Raven Press, Ltd, 1995 773-785.
31 Simerly RB, Swanson LW. Projections of the medial preoptic nucleus: A Phaseolus vulgaris leucoagglutinin anterograde tract-tracing study in the rat. J Comp Neurol 1988; 270: 209-242.

32 Vertes RP. PHA-L analysis of projections from the supramammillary nucleus in the rat. J Comp Neurol 1992; 326: 595-622.

33 Cullinan WE, Herman JP, Watson SJ. Ventral subicular interaction with the hypothalamic paraventricular nucleus: evidence for a relay in the bed nucleus of the stria terminalis. J Comp Neurol 1993; 332: $1-20$.

34 Moga M, Saper C. Neuropeptide-immunoreactive neurons projecting to the paraventricular hypothalamic nucleus in the rat. J Comp Neurol 1994; 346: 137-150.

35 Sawchenko PE, Swanson LW. The organization of the forebrain afferents to the paraventricular and supraoptic nuclei. J Comp Neurol 1983; 218: 121-144.

36 Swanson LW, Cowan WM. The connections of the septal region in the rat. J Comp Neurol 1979; 186: 621-656.

37 Weller KL, Smith DA. Afferent connections to the bed nucleus of the stria terminalis. Brain Res 1982; 232: 255-270.

38 Stefanacci L, Farb CR, Pitkanen A et al. Projections from the lateral nucleus to the basal nucleus of the amygdala: a light and electron microscopic PHA-L study in the rat. J Comp Neurol 1992; 323: 586-601.

39 Pitkanen A, Stefanacci L, Farb CR et al. Intrinsic connections of the rat amygdaloid complex: projections originating in the lateral nucleus. J Comp Neurol 1995; 356: 288-310.

40 LeDoux JE, Ruggiero DA, Reis DJ. Projections to the subcortical forebrain from anatomically defined regions of the medial geniculate body in the rat. J Comp Neurol 1985; 242: 182-213.

41 LeDoux JE, Farb C, Ruggiero DA. Topographic organization of neurons in the acoustic thalamus that project to the amygdala. J Neurosci 1990; 10: 1043-1054.

42 Campeau S, Akil H, Watson SJ. Lesions of the auditory thalamus specifically block corticosterone release and induction of c-fos mRNA in the forebrain associated with loud noise stress in rats. Soc Neurosci Abstr 1996; 22: 1148 